\title{
San Agustín en el XIV Congreso Internacional de Filosofía
}

\author{
(Viena 2 al 9 de septiembre, 1968)
}

Sobre el ambiente general, clima espiritual y temática más sobresaliente del XIV Congreso Internacional de Filosofía celebrado en Viena he informado en otro lugar ${ }^{1}$, al que gustosamente remito al lector interesado en conocerlos. Como allí indiqué, fue una "reunión sin encuentro", un choque de ideologías más que intercambio, diálogo o enriquecimiento filosóficos. Para los que ingenuamente pensaban y daban ya por periclitadas las ideologías ha sido una buena lección. El mundo no funciona de por sí, en un juego dialéctico necesario de infraestructuras o supraestructuras, sino dirigido y llevado por ideales más que por ideas, por ideologías y creencias más que por sistemas reflexivos en los que se tenga como meta la libertad humana. El hombre es un animal de creencias y sobre ellas monta su andamiaje reflexivo para justificanlas, cambiarlas o extenderlas. Yo no diría, por ello, que dicho Congreso fue de los más "aburridos y estériles desde hace tiempos", como se escribió en algún informe inmediato al mismo (cf. Die Zeit, 13, IX). Espero, por el contrario, que a muchos filósofos occidentales el hecbo del Congreso habrá of recidos serios motivos de reflexión, más tal vez que muchos temas previstos teóricamente en el Programa. El haberse desarrollado en un aire cargado de tensiones políticas, estribando en un subsuelo de desconfianza esencial, donde a las palabras se les buscaba terceras intenciones, debe hacernos comprender, definitivamente, que al hombre le es muy difícil - lo que Kant decía ya imposible - hablar objetivamente de "la cosa en sí". ¿Dónde está esa señora?

Sin embargo, como en todos los Congresos, uno de los frutos siempre seguros y casi automáticos es el conocimiento directo de personas y la labor pormenorizada que se hace - sin la aglomeración masificada de las Sesiones plenarias y Coloquios generales- en las secciones particulares de trabajo. Esto ocurrió también en el XIV Congreso Internacional de Filosofía. Los filósofos que figuraban

1 Véase ARBor (C. S. I. C.), Madrid 1968, n. ${ }^{\circ}$ 273-74 (1967), p. 75-82. 
como punto expreso de comunicaciones eran: Platón, Aristóteles, Agustín, Tomás de Aquino, Leibniz, Kant, Hegel, Rosmini y Feuerbach. Había una sección de "miscelánea" para los innominados y para las comunicaciones que no llegaron a tiempo para la clasificación. Marx figuraba aparte, solitario y señero. A Marx se le dedicó la parte más sobresaliente del Congreso, bien como homenaje explícitamente planeado, bien tal vez además como punto de confluencia sobre el que pudiera iniciarse el diálogo a escala "internacional". Fue el tema de los primeros Coloquios generales que, por parte de intencionado encantamiento, fue transformado en el tema del "humanismo marxista". El mago de esa transformación fue Oiserman, jefe de la representación rusa, y a quien Die Zeit llamó muy gráficamente "el tigre del Congreso". Lo que fue tal vez pensado como lugar intelectual de encuentro vino a resultar así piedra de choque, y el Congreso quedó definido ya como clima y como fracaso, en el primer Coloquio general.

En las líneas que van a seguir me limitaré a informar un poco detalladamente sobre la sección particular o círculo de trabajo (Arbeitskreis, decía en alemán), dedicado a San Agustín.

\section{La metafísica de Agustín.}

Lo primero que es preciso notar fue la ausencia de los mejores agustinólogos d: fama mundial. Sin querer menospreciar la importancia de los que mandaron comunicaciones o, siendo agustinólogos, las mandaron a otra sección (v. g. Sciacca, que figuraba en la sección de Rosmini), el único de los presentes que podía representarlos fue Rudolf Berlinger, que formaba parte de la sección y era el presidente de la misma. Los que mandaron o leyeron sus ponencias fueron: P. Hadot (Francia), T. Imamichi (Japón), W. Theiler (Suiza), W. Beierwaltes (Alemania occidental), J. Mader (Austria), J. C. Cooper (USA), J. Mourant (USA) y C. Conçalves (Portugal). W. Theiler cuyo tema era Orígenes y la Psicología agustiniana no pudo asistir por encontrarse enfermo. La ponencia de J. Mader El concepto de persona en Agustín, no se leyó. A las comunicaciones de W. Beierwaltes ("Interpretación agustiniana del Sapiencia, 11, 21") y de J. C. Cooper ("¿Por qué escribió Agustín los libros XI al XII de las Confesiones?") no pude asistir. De la intervención del D. C. Gonçalves, se publica en este número de Estzadio Agustiniano un resumen escrito por el mismo autor (cf. p. 545). También se publica en este númera (cf. p. 553) la comunicación del Prof. P. Enrique Rivera de Ventosa, que aunque no se presentó en la "sección de Agustín", sino en la de "La Filosofía de la Cultura", exponía un tema expresamente agustiniano, como podirá ver el lector.

El presente informe queda, por ello, obligadamente circunscrito a la interven- 
ción de Berlinger, como presidente, y a las comunicaciones de Hadot, Imamichi y Mourant.

Berlinger hizo la presentación general y habló largamente sobre el nombre y significación del ser en el comentario de Agustín a la famosa frase del Exodo "Ego sum qui sum". Aunque en la novedad la "conferencia" de Berlinger era un auténtico "refrito" 2, revistió sin embargo un extraordinario interés dada la profundidad a que Berlinger la sabe llevar y sobre todo la conciencia de actualidad en que, sin expresa referencia externa, Berlinger la logra situar y desenvolver. Añadamos que para muchos, no al tanto de las publicaciones agustinianas, contenía además el aliciente de la novedad.

En resumen Berlinger vino a decir lo siguiente: La problemática de Agustín nace del planteamiento de la dialéctica entre fe y saber que se traspone en términos filosóficos en la dialéctica de la eternidad y el tiempo. El ser como tal, el ser sin adjetivos ni limitación, el nombre ser - "Magnum hoc verbum", dice Agustín-y la pregunta por su significado es la razón dinámica (das bewegende Motiv) de todo el filosofar agustiniano. A través del conocimiento directo de lo que está ahí, de la existencia concreta (Daseina), de la posibilidad dada en nosotros de su aprehensión y nominación, de la simple nominación misma de los entes, se nos revela la existencia de una posesión cognoscitiva del ser absoluto (des absoluten Seins selbst). De ahí nace la dialéctica entre el ser y el ente, es decir, el ser y el "siendo" (Seiendes), eternidad y tiempo, Dios y mundo. Esta dialéctica es tensión permanente y en ello consiste el filosofar humano. Desde la atemporalidad del ser, esa palabra atemporal funda la temporalidad e historicidad de los entes, es decir, del siendo. Con este planteamiento Berlinger lee y cita los muy selectos y conocidos textos de Agustín sobre el tiempo y la fugacidad de las cosas que, desde la constatación de su flujo y movilidad, nos remiten a la permanencia del ipsum esse, del esse solum, del esse germanum, de la incommutabilis substantid. Ese ser tuténtico e inconmutable es Dios, el tú intemporal, transcendente, que se inserta en la historia y teje, desde la eternidad, la presencia cotidiana, originándola y transformándola: vocans temporales, faciens aeternos, dice Agustín de la trascendencia del Verbo con respeto a los tiempos.

El hombre representa, por ello el lugar ontológico donde esta dialéctica tiene su asiento y su dinámica. Es "medio" en el sentido más fuerte de esta palabra.

2 El autor había ya tocado el tema fundamentalmente en su libro Augustins dialogische Metaphysik, Frankfurt/M. 1962; lo ataca expresamente bajo el título: Der Name Sein-Prologomena zu Augustins Exodus-Metaphysik en la obra de colaboración Wirklichkeit der Mitte, dedicada como homenaje a Augusto Veter (München 1968). A su vez eista redacción se presentaba como el texto que habí i servido para unas conferencias habidas por invitación del Archivo de Husserl de la Universidad de Colonia en el semestre de invierno de 1963-64, en la Facultad filosófica de la Universidad de Viena. Finalmente, parte de este estudio ha aparecido tambiẹn en español en la revista Augustinus 49-52 (1968) 99-108. 
Y al serlo puede su "mediación" ser camino de ascensión o de hundimiento. Es el sentido del socorrido "experimentum medietatis" de que Agustín nos habla en el libro XII De Trinitate ${ }^{B}$.

La exposioión de Berlinger resultó, pues, como un auténtico prolegómenos a toda la metafísica agustiniana y a una variedad de problemas que de ella y en ella se enlazan: historicidad, vocación, dialéctica trinitaria, funcionalidad del filosofar, etc.

Lamentablemente esa carga de apuntes y sugerencias no suscitó ningún coloquio serio, sino alguna pregunta marginal sin interés directo sobre el tema. Porque el verdadero punto neurálgico del planteamiento de Berlinger es el modo y el alcance del apriori agustiniano y la manera de poder justificarlo sin un "salto cualitativo". De aquí que quede a su vez condicionado el modo de la "inversión" que Berlinger propugna para una nueva filosofía del ser, de inspiración agustiniana, que desarticule, llevándola a los límites de sí misma, la presunta autonomización del mundo histórico como inmanencia pura y "mediación" de sí mismo. Cierto que esta clarificación de Berlinger de la concepción del ser no hubiera sido posible sin el ahondamiento en el pensamiento moderno y en los problemas que ha suscitado la hermenéutica fenomenológica del "ser y el tiempo", es decir, la comprensión de la historicidad:

La ponencia de Imamichi llevaba por título Augustins Problem der Transzendenz im Bezug auf die Wabrbeitsgestalt (El problema de la transcendencia en Agustin en relación con la forma de [darse] la verdad)! T. Imamichi es Profesor en la Universidad de Tokio, Director del Instituto de Estética de la misma y, por lo que yo conozco, ha escrito un interesante libro cuyo tíulo en alemán es Betrachtungen über das Eine (Meditaciones sobre el Uno), Universidad de Tokio 1968. Ahora prepara una obra sobre Agustín, de la que esta ponencia forma parte central. Tal vez por esta separación de otro contexto más amplio sea bastante difícil comprender lo que en ella quiso fundamentalmente decir o concretar. La exposición siguió este orden: Examen de la "paradoja del corazón nuevo" (das Paradox cordis novi). Se nos dice dabo vobis cor novum y facite cor novum. Esta paradoja es la misma que la de la Gracia y la Libertad explanada por Agustín en el De libero arbitrio, sobre todo en los capítulos XVI y XXII. Alargando el tema se plantea la disputa de Agustín con Pelagio. Para Agustín, el Dios de Pelagio es el mismo Dios de Aristóteles, tal como se nos da en la Etica a Nicómaco: el ser que está sentado allá en los cielos, sobre las estrellas, y da leyes a los hombres. Piensa, sin embargo, el Profesor Imamichi que late aquí una gran confusión: el

3 R. BERLINGUER alude en algún lugar a la obra del WALTHER REHMS, Experimentum medietatis (Studien zur Geistes- und Literaturgeschichte des 19. Tahrhunders, München 1947) y a su posible eco de la frase de Agustín en el De Trinitate XII, 11, 16 (P. L, 32, 1006 f). 
Dios aristotélico es distinto del Dios de Pelagio. El Dios aristotélico es vónoıs von el contrario, un Juez, su norma es la ley y su acto esencial el Juicio. Así la verdad para Aristóteles es descripción de la forma del fenómeno, mientras para Pelagio es el juicio de distinción entre el Bien y el Mal. Para Agustín la verdad no es ninguna de ambas cosas. No es descripción, porque la realidad es fugitiva y no puede encuadrarse; el campo de observación es siempre limitado y la realidad huye y se escapa de nuestra visión (Hinsicht). Tampoco se apela a un Juicio recto o verdadero sino al "abismo de tu juicio" (Conf. VII, VI). Relaciona entonces el Prof. Imamichi a Agustín con Platón sobre el texto "Yo juzgo desde o por la verdad que está sobre mi mente. El juicio sobre lo mudabile es recto pero no se podría decir verdadiero (Conf. VII, XVIII, XIIIt- Y es aquí ouando surge de lleno el problema de la transcendencia. Cito literalmente las palabras del Profesor Imamichi, para no exponerme a un resumen posiblemente increíble: "Se habla demasiado aprisa sobre la identidad de la Inmanencia y de la Trascendencia en Agustín al citar la frase interior intimo meo et superior super me (sic., R. F.). Pero esta identidad no se puede decir que es característicamente agustiniana. Se encuentra en el libro III de las Confesiones en el que él mismo dice que todavía no era cristiano (in dem er selbst meinte, dass er noch nicht christlich war). Esta frase es propiamente platónica... El Dios de Platón está por encima de todo ser y del mismo mundo de las ideas. La identidad de Inmanencia y Trascendencia se explica siempre en Platón por una apelación e interpretación del mito. La relación del Dios platónico con el hombre era asunto de la "mántica" más interior. De ahí que la trascendencia en Platón era ciertamente primero "interior intimo meo" y después "superior super me". Pero la orientación de la conciencia de Agustín es justamente todo lo contrario. Dios viene a mí, y por ello, habita y vive en mí (Conf. X). El Dios "superior super me" tiene que venir a mí para ser "intexior". El hombre que piensa y retorna a sí (cogitani et redeunti) es el punto de encuentro de la trascendencia (Conf. VII, VIII, XI). La primacía óntica de la trascendehcia y la primacía lógica de la inmanencia integran la realización del Uno en el espíritu humano". Este es el horizonte en el que el diabo y el facite del cor novum pueden ser idénticos, es decir, en el que el sujeto y el objeto plenifican juntamente una nueva realidad (Sache). "Esta reducción henológica - cito otra vez literalmente- hacia el Uno es la vida, el camino para el pensamiento y con ello su forma de la verdad".

Repito que sería necesario conocer un contexto más amplio para poder aceptar o criticar todo esto, aparte de las elementales incorrecciones históricas y de citas. Dado lo sugestivo del tema, quise dialogar aparte, al final de la sesión, con el Prof. Imamichi. No hubo posibilidad a disculpas del tiempo, y con la mejor amabilidad y atención japonesas me remitió a su futuro libro, del que Dios 
dirá cuándo y cómo los agustinólogos se podrán hacer cuestión. Es claro que nos encontramos con una mentalidad distinta de la que acostumbra leer a San Agustín. Sería muy fácil destruir toda esta construcción con las conocidas distinciones de un orden natural y un orden sobrenautral, orden óntico y orden de consciencia, etc. Pero lo incitador es justamente todo lo contrario: la comprensión, si es que es posible, de la wonidad, sobre la que montamos esas distinciones.

\section{CUESTIONES HISTÓRICAS Y DE EXÉGESIS.}

Pierre Hadot nos leyó íntegramente su ponencia sobre La presentación del platonismo becha por Agustín. Después de desprenderse rápidamente de la "bibliografía", que es necesario conocer pero no perderse en ella, — dijo-, el Prof. Hadot analizó solamente tres lugares donde Agustín hace un resumen de la doctrina platónica: el Contra Acadiemicos, De Vera Religione y la carta 118. Aludió, sin poder ocuparse de él, al resumen del libro VIII de la Ciudad de Dios.

Los esquemas que condicionan la estructura de estos resúmenes son dos: Primero, la oposición entre lo sensible y lo inteligible o sea, lo mudable y lo inmutable; y segundo, la división de la Filosofía en tres partes: Física, Lógica y Etica.

En cada resumen el acento se pone sobre aquello que más interesa a Agustín, sobre aquello que más le interesa subrayar según el tratado o exposición de la verdad que persigue. Esta presentación del Platonismo que el autor la estima francamente tradicional, es decir, que prácticamente no se utiliza en ella ningún elemento neoplatónico. Como en los resúmenes clásicos de la "física" platónica, el alma está situada en una posición intermedia: por un lado, descubire que es cambiante y mudabile, como el mundo sensible (progresa, razona, etc.), y por otro, constata que participa de la inmutabilidad del mundo inteligible en la medida en que "percibe la verdad que habita en ella". Lo novedoso en estos resúmenes de Agustín es que la "sistematización" es propiamente agustiniana. Hay elementos tomados de Cicerón, analogía de Apuleyo, pero en ninguna parte (exceptuando un solo pasaje de Clemente de Alejandría) se encuentra una presentación del platonismo que acentúe tan claramente como en Agustín que Dias es el objeto de las tres partes de la Filosofía.

Lo importante es que Agustín identifica el contenido del platonismo en la forma en que él lo ha sistematizado con el contenido del mensaje cristiano (Conf. XII) y Agustín lo afirmó explícitamente en el De Vera Religione y en la carta 118. "Para subrayar la paradoja - dijo literalmente Hadot- se podría expresar de la forma siguiente: el Cristianismo aparece en esta perspectiva como una especie de platonismo para el pueblo, es decir, como un medio de extender a la masa un 
conocimiento que hasta entonces había estado reservado a una élite". Sólo Cristo, como verdad encarnada, y dirigiéndose a los sentidos de los hombres con sus milagros, fue capaz de comunicar la verdad del mundo inteligible, la verdad de lo que está por encima de los sentidos.

A su vez, el intento de Agustín por formular, en constante y renovado esfuerzo, en términos platónicos la doctrina cristiana, correspondía a la tentativa de organizar y estructurar los principios rectores de su propio pensamiento. Puede verse así toda la doctrina agustiniana como apoyada sobre un pequeño número de principios: el ser verdadero no cambia, lo que cambia es inferior y derivado, ol alma debe dirigirse a lo que no cambia y apartarse de lo que cambia, etc. Ello da una gran sencillez de estructura a toda la Flilosofa agustiniana. Las apelaciones, recursos y referencias que tan variadamente hace Agustín a las doctrinas neoplatónicas son siempre interesantes y frecuentemente muy sutiles. Pero no nos deben obnubilar u ocultar esta sencillez estructural que domina todo el pensamiento agustiniano. "La grandeza de Agustín - concluyó el ponente- consiste en haber sabido desarrollar todas las consecuencias de esos principios tradicionales, cuya banalidad era sólo aparente, y haberles dado un contenido nuevo gracias a la experiencia cristiana vivida y revivida cada vez con más intensidad".

Un buen tema de exégesis agustiniana es el que presentó John A. Mourant a propósito del De Immortalitate Animae. El hecho ce ser un libro que Agustín mismo dio algo así como al anatema, al decir que era un borrón, que apenas si era casi inteligible para sí mismo, ha traído como consecuencia la desatención a ese librito extraño, casi el olvido. Nos debería interesar aunque nada más fuera por eso: por saber cómo Agustín hacía sus "borrones", cómo enhebraba sus pensamientos en esquemas y silogismos puramente "racionales", cómo construía la armadura de sus obras antes de llenarlas de carne y sangre "agustinianas". Pero no ha ocurrido así. Los agustinólogos se han preocupado hasta de hacernos una posible construcción de lo que sería el De Pulchro et Apto, del que no nos queda ni rastro expreso, a desentrañar los esquemas previos subyacentes en obras perfectas, pero el De Immortalitate animae que está ahí como tal, carece casi en absoluto de bibliografía. Y ello con ser un punto decisivo en la evolución de Agustín, y con comenzar a sernos problema la situación misma cronológica del libro. En algunas versiones de las Obras de Agustín, en las que están todas las del primer período, ni siquiera se ha traducido. Pero, en fin, dejo la palabra a la ponencia de J. A. Mourant, que tal vez suscite algún corajudo que se enfrente de verdad con el tema y el problema.

El título de la comunicación del Prof. Mourant era: The Uniqueness of "De Immortalitate animae" (La singularidad del "De Immortalitate animae"). Dicha "singularidad" es evidente ante el mero contraste con los otros escritos de ese tiempo, si es que se da por admitida la fecha que se nos dice de su composición, 
o sea, entre el miércoles de ceniza y el domingo de resurrección del 387. Es una obra que no encaja con ninguna de las otras de ese tiempo, ni en la forma ni en el contenido. No está en forma de diálogo, tiene un estilo y método distintos, es oscura, etc. En ouanto al contenido, no tiene el clima espiritual de las preocupaciones de Agustín, ni expresiones religiosas, ni plegarias, ni jaculatorias, ni referencias escriturísticas. ¡Cuán lejos de la oración larga y mantenida con que se inician los Soliloquios! El nombre de "Dios" aparece una sola vez $(13,22)$, y cuando es habla de "razón", "veritas" o "summa essentia" igual pueden identificarse con el contenido agustiniano de Dios que con el concepto del "Uno" o del "Nous" o de lo "Bueno" plotinianos. Por otra parte es la más filosófica, mejor dicho, la casi exclusivamente filosófica, de todas las obras de ese período. Ante este hecho de la singularidad, bien puesto y analizado, el ponente no sugiere ninguna perspectiva de posición personal. Se lanzan una serie de conjeturas sobre todo acerca de la fecha "admitida" de la composición, pero sin inclinarse decisivamente por ninguna. Todo se queda en un "acaso", "tal vez", "podría ser". Pero la aportación está hecha. Consiste en haber hecho ver que hay ahí una verdadera cuestión que estudiar y sobre la que se volvería a plantear otra vez la vieja tesis de Alfaric. El ponente cree que en este libro se libraría la clave decisiva en pro o en contra, más bien en pro.

\section{MARgINAL.}

De la sección dedicada a Agustín salíamos el día 5 por la tarde. La impresión general fue más bien de pobreza, de falta de interés y de "ausencia de los mejores". Quedaban todavía cuatro días de Congreso. A pesar de los amagos de que podría disolverse o quebrarse, el. Congreso seguía su programa, cada día menos ilusionado, más decaído. Para los que todavía podían conservar entusiasmo era una llamada inmediata a la irritación. Pero sólo los estudiantes "rebeldes" decían en alto lo que otros susurraban en los rincones. El "tigre del Congreso" seguía siendo tigre, si bien el testaferro tenía que ser ahora Schaff, el digno marxista polaco Schaff. La sombra de Marx, alargada como la de los cipreses, seguía oscureciendo otros costados ricos del Congreso, por ejemplo, La Logística, la Filosofía del Lenguaje, de las Ciencias de la Naturaleza, etc. Las sesiones plenarias ya no iban siendo plenarias, ni los Coloquios generales eran coloquios. Quedaban "en su ser" las secciones particulares como esta de Agustín, o como la de Hegel o como la de Fiolosofía de la Religión. ¿No habría otra manera de organizar los Congresos en la que lo plenario y general, más bien que planeado, fuera resultado de lo particular? La triste lección de Viena podría bien invitar a la Federación Internacional de Sociedades de Filosofía a que fuera la última,

R. FLÓREZ 